\title{
Toll-Like Receptor Signaling Is Critical for Wallerian Degeneration and Functional Recovery after Peripheral Nerve Injury
}

\author{
Audrey Boivin, Isabelle Pineau, Benoit Barrette, Mohammed Filali, Nicolas Vallières, Serge Rivest, and Steve Lacroix \\ Laboratory of Molecular Endocrinology, CHUL Research Center, and Department of Anatomy and Physiology, Faculty of Medicine, Laval University, Ste- \\ Foy, Québec, Canada G1V 4G2
}

Toll-like receptors (TLRs) bind specific components conserved among microorganisms as well as endogenous ligands produced by necrotic cells, injured axons, and the extracellular matrix. Here, we investigated whether TLRs are involved in regulating the immune response, Wallerian degeneration (WD), and nerve regeneration after sciatic nerve lesion. Early expression of interleukin- $1 \beta$ and monocyte chemoattractant protein-1 was compromised in the sciatic nerve distal stump of mice deficient in TLR signaling. In addition, significantly fewer macrophages were recruited and/or activated in the sciatic nerve distal stump of TLR2-, TLR4-, and MyD88-deficient mice compared with wild-type littermates, whereas WD, axonal regeneration, and recovery of locomotor function were impaired. In contrast, animals that received a single microinjection of TLR2 and TLR4 ligands at the site of sciatic nerve lesion had faster clearance of the degenerating myelin and recovered earlier than saline-injected control rats. Finally, rats that had altered innate immune response through dexamethasone treatment exhibited three times more myelin debris in their sciatic nerve distal stump and a significant delay in recovery of locomotor function. Our results provide strong evidence that TLR signaling plays a critical role in orchestrating the innate immune response leading to efficient and rapid clearance of inhibitory myelin debris and nerve regeneration.

Key words: sciatic nerve; macrophages; lipopolysaccharide; zymosan; myelin inhibitors; axonal regeneration

\section{Introduction}

Although the cellular and molecular mechanisms regulating Wallerian degeneration (WD) and axonal regeneration in the injured peripheral nerve have been studied extensively, the identity of the molecules initiating these responses has remained elusive. Work done with various animal models, including slow WD $\left(\mathrm{Wld}^{\mathrm{s}}\right)$ mutant mice, has been instrumental in revealing how axonal loss rapidly leads to a series of responses implicating non-neuronal cells, including the dedifferentiation, proliferation, and activation of Schwann cells; the activation of resident endoneurial macrophages; and the recruitment of immune cells from the periphery (Heumann et al., 1987; Lunn et al., 1989; Brown et al., 1991; Mueller et al., 2003). Of particular interest are studies that linked these cellular responses to the secretion of specific proinflammatory cytokines and chemokines (Lindholm et al., 1987; Reynolds and Woolf, 1993; Fu and Gordon, 1997; Carroll and Frohnert, 1998; Liefner et al., 2000; Siebert et al., 2000; Perrin et al., 2005).

Received July 3, 2007; revised Sept. 21, 2007; accepted 0ct. 1, 2007.

This work was supported by the Canadian Institutes of Health Research (CIHR). S.L. was supported by a Career Award from the Rx\&D Health Research Foundation and the CIHR. S.R. holds a Canadian Research Chair in neuroimmunology. We are grateful to Dr. Shizuo Akira (Department of Host Defense, Osaka, Japan) for the generous gift of a breeding pair of MyD88-ko mice. We thank Nadia Fortin, Jessie Beaupré, and Alain St-Pierre for technical assistance. We also acknowledge the contribution of the Gene Quantification core laboratory of the Centre de Génomique de Québec. Finally, we thank Marc-André Laniel for help editing this manuscript.

Correspondence should be addressed to Dr. Steve Lacroix, CHUL Research Center and Laval University, 2705 Laurier Boulevard, Ste-Foy, Québec, Canada G1V 4G2. E-mail: Steve.Lacroix@crchul.ulaval.ca. D0I:10.1523/JNEUROSCI.3027-07.2007

Copyright $\odot 2007$ Society for Neuroscience $\quad$ 0270-6474/07/2712565-12\$15.00/0
Although this has been the object of longstanding controversies, it is now well accepted that both macrophages (resident and hematogenous) and Schwann cells participate in the clearance of myelin debris and inhibitors of axonal regeneration associated with it during WD in the injured peripheral nervous system (PNS) (Beuche and Friede, 1984; Stoll et al., 1989; FernandezValle et al., 1995; Bruck et al., 1996). We recently demonstrated that proinflammatory cytokines/chemokines interleukin- $1 \beta$ (IL$1 \beta)$, monocyte chemoattractant protein-1 (MCP-1), and macrophage inflammatory protein-1 $\alpha$ (MIP- $1 \alpha)$ regulate myelin debris clearance after sciatic nerve lesion in mice (Perrin et al., 2005). Several inflammatory cytokines/chemokines are produced as early as $1 \mathrm{~h}$ after peripheral nerve lesion, with expression levels peaking at $\sim 24 \mathrm{~h}$ (Carroll and Frohnert, 1998; Shamash et al., 2002; Stoll et al., 2002; Perrin et al., 2005). Studies have revealed that endoneurial cells such as Schwann cells and resident macrophages are responsible for the initial production of cytokines and chemokines in injured peripheral nerves (Taskinen and Roytta, 2000; Subang and Richardson, 2001; Shamash et al., 2002). Hematogenous macrophages, which require at least $2 \mathrm{~d}$ to invade injured peripheral nerves, contribute to maintain their production at later times after injury. One important issue that remains to be resolved, however, is the identification of the signals and receptors mediating the expression of the proinflammatory cytokines and chemokines that regulate WD and peripheral nerve regeneration after injury.

Toll-like receptors (TLRs) and activation of the nuclear 
Table 1. Overview of the number of animals included in different experiments

\begin{tabular}{|c|c|c|c|c|c|c|c|c|c|c|}
\hline \multirow[b]{3}{*}{ Experiment/group } & \multirow[b]{3}{*}{ Noninjured } & \multicolumn{9}{|c|}{ Methodology } \\
\hline & & \multicolumn{3}{|l|}{ ISH } & \multirow[b]{2}{*}{ qRT-PCR (24 h) } & \multirow[b]{2}{*}{ Arrays (24 h) } & \multicolumn{2}{|c|}{ Immunohistochemistry } & \multirow[b]{2}{*}{ Histology (7 d) } & \multirow[b]{2}{*}{ Behavior (49 d) } \\
\hline & & $1.5 \mathrm{~h}$ & $6 \mathrm{~h}$ & $24 \mathrm{~h}$ & & & $3 d$ & $4 d$ & & \\
\hline \multicolumn{11}{|l|}{ Experiment 1} \\
\hline C57BL/6] & 2 & 6 & & 6 & 5 & 3 & & 6 & 8 & 12 \\
\hline TLR2-ko & 2 & 5 & & 5 & 5 & 3 & & & 8 & 12 \\
\hline MyD88-ko & 2 & 5 & & 5 & 3 & 3 & & 6 & 8 & 12 \\
\hline $\mathrm{C} 3 \mathrm{H} / \mathrm{HeOUJ}$ & 1 & 4 & & 5 & 5 & 3 & & & 8 & 12 \\
\hline $\mathrm{TLR}^{\mathrm{d}}$ & 1 & 4 & & 5 & 5 & 3 & & & 8 & 12 \\
\hline \multicolumn{11}{|l|}{ Experiment 2} \\
\hline Lesion only & & & & & & & & & 6 & 10 \\
\hline PBS & & $2^{a}$ & $8^{a}$ & & & & $10^{b}$ & & 6 & 10 \\
\hline Zymosan & & $2^{a}$ & $8^{a}$ & & & & $10^{b}$ & & 6 & 10 \\
\hline LPS & & $2^{a}$ & $8^{a}$ & & & & $10^{b}$ & & 7 & 10 \\
\hline \multicolumn{11}{|l|}{ Experiment 3} \\
\hline Control & & & & & & & & & 6 & 10 \\
\hline DEX & 2 & & & & & & & & 5 & 11 \\
\hline MP & 2 & & & & & & & & 6 & 11 \\
\hline
\end{tabular}

${ }^{a}$ Uninjured rats given microinjections of PBS, zymosan, or LPS into their left sciatic nerve.

${ }^{b}$ Two of these 10 rats were uninjured.

factor $-\kappa \mathrm{B}(\mathrm{NF}-\kappa \mathrm{B})$ signaling pathway play a critical role in the transcriptional activation of a large family of inflammatory ligands in response to pathogen-associated molecular patterns (PAMPs) (Nguyen et al., 2002). Interestingly, emerging evidence suggests that TLRs may also mediate responses to nonpathogenic ligands, such as necrotic cells, heat shock proteins (HSP60, HSP70), and extracellular matrix (ECM) components (e.g., fibronectin, hyaluronic acid, and heparan sulfate) (for review, see Takeda et al., 2003). Perhaps even more interesting are the facts that necrotic cells are abundant at sites of nerve injury, HSP60 and HSP70 are locally expressed by injured axons, and ECM components are produced at sites of inflammation in response to tissue damage (Willis et al., 2005). In culture, Schwann cells treated with necrotic neuronal cells become activated and express proinflammatory genes through TLR2 and TLR3 pathways (Lee et al., 2006). Furthermore, Karanth et al. (2006) have demonstrated that molecules derived from nerve homogenates induce MCP-1 expression in primary Schwann cells and that activity in nerve homogenates is partially inhibited by TLR4 functionblocking antibodies. Another study has recently shown that intact ECM inhibits TLR4 activation and that degradation of ECM by proteases not only relieves TLR4 inhibition but generates endogenous soluble agonists (e.g., heparan sulfate) that stimulate the receptor (Brunn et al., 2005). Inducing inflammation through injection of the TLR2 agonist zymosan into the eye was shown to promote retinal ganglion cell regeneration after optic nerve crush injury (Leon et al., 2000), whereas systemic injections of the TLR4 agonist lipopolysaccharide (LPS) was able to accelerate myelin phagocytosis during WD in the injured spinal cord (Vallières et al., 2006). Together, these findings suggest that endogenous ligands present at sites of nerve injury may activate specific TLRs and initiate innate immune responses during WD.

The characterization of the signals that regulate immune responses during WD could have a major impact on the development of new strategies to treat PNS and CNS injuries. Here, we demonstrate that deficiency in TLR signaling delayed macrophage recruitment/activation, myelin debris clearance, axonal regeneration, and locomotor recovery after sciatic nerve lesion. On the other hand, activation of TLR2 or TLR4 accelerated phagocytosis of myelin debris and recovery of peripheral nerve functions. Finally, we show that alteration of immune responses via administration of the glucocorticoid agent dexamethasone (DEX) delayed functional recovery.

\section{Materials and Methods \\ Animals}

A total of 208 adult male mice and 178 adult male rats (8-12 weeks old) were used in this study. $\mathrm{C} 3 \mathrm{H} / \mathrm{HeJ}$ (TLR4 mutant mice) and their wildtype counterparts, $\mathrm{C} 3 \mathrm{H} / \mathrm{HeOUJ}$ mice, were purchased from The Jackson Laboratory (Bar Harbor, ME). TLR2-knock-out (ko) and MyD88-ko mice in the C57BL/6J background (i.e., backcrossed with C57BL/6J mice for at least nine generations) were obtained from The Jackson Laboratory and Dr. S. Akira (Department of Host Defense, Osaka, Japan), respectively. These two colonies of mice were maintained at the CHUL Research Center until they were used for the present experiments. C57BL/6J mice from The Jackson Laboratory were used as controls for TLR2 and MyD88 mice. Rats were purchased from Charles River Laboratories (Montréal, Québec, Canada). Mice and rats had ad libitum access to food and water. All surgical procedures were approved by the Laval University Animal Care Committee and followed Canadian Council on Animal Care guidelines. The distribution of these animals among the three different sets of experiments performed in the present study and time points at which animals were killed are reported in Table 1.

\section{Surgeries and animal treatment}

Sciatic nerve microcrush lesions. Mice and rats were deeply anesthetized with isoflurane and underwent a microcrush lesion of their left sciatic nerve at the mid-thigh level. The sciatic nerve was exposed, and a 10-0 (for mice) or 7-0 (for rats) suture was used to tie a knot to completely constrict the nerve for $60 \mathrm{~s}$, therefore allowing complete transection of neural fibers without breaking the epineurium. The suture was then carefully released, and the lesion site was marked with a 10-0 Ethilon suture (Ethicon, Somerville, NJ) passed through the epineurium only. For sham-operated animals, the sciatic nerve was left untouched.

Sciatic nerve microinjections. Immediately after microcrush lesion, rats used for experiment 2 were given microinjections of zymosan $(2 \mu \mathrm{g} / \mu \mathrm{l}$; Sigma-Aldrich Canada, Oakville, Ontario, Canada), LPS $(2 \mu \mathrm{g} / \mu \mathrm{l}$; Sigma-Aldrich Canada), or PBS in a final volume of $1 \mu$ l. Microinjections were made at the site of lesion through a pulled-glass micropipette (30 $\mu \mathrm{m}$ external diameter) connected to a $2 \mu \mathrm{l}$ Hamilton syringe. In addition, microinjections were also performed in uninjured rats to investigate the effects of zymosan and LPS on cytokine/chemokine expression and leukocyte recruitment.

Injections of glucocorticoid agents. For the purpose of experiment 3, rats with sciatic nerve lesions were treated with DEX, methylprednisolone (MP), or saline. DEX sodium phosphate (Sandoz, Boucherville, Québec, 
Canada) at $10 \mathrm{mg} / \mathrm{kg}$ was injected intraperitoneally daily for 5 consecutive days, starting immediately after the lesion. For MP, rats first received an intravenous bolus of MP sodium succinate (Solu-Medrol; Pharmacia Canada, Mississauga, Ontario, Canada) at $30 \mathrm{mg} / \mathrm{kg}$ at $1 \mathrm{~h}$ after lesion, followed by intraperitoneal injections $(64.8 \mathrm{mg} / \mathrm{kg})$ every $12 \mathrm{~h}$ during the first $48 \mathrm{~h}$. This regimen is similar to the one used to treat patients with spinal cord injury (SCI) in the second and third NASCIS (National Acute Spinal Cord Injury Study; a $30 \mathrm{mg} / \mathrm{kg}$ intravenous bolus followed by a continuous infusion of $5.4 \mathrm{mg} / \mathrm{kg} / \mathrm{h}$ for $48 \mathrm{~h}$ ) and current guidelines for clinical treatment of SCI and acute traumatic optic neuropathy (Bracken et al., 1990, 1997; Steinsapir, 2006). Animals given injections of $0.9 \%$ saline constituted the control group. Some sham-operated animals treated with glucocorticoid agents were also included to confirm that immunosuppression had no effect on sensorimotor activity in the absence of a lesion.

\section{Tissue processing}

For the experiments dealing with in situ hybridization (ISH), mice and rats were overdosed with a mixture of ketamine and xylazine and transcardially perfused with $0.9 \%$ saline solution followed by $4 \%$ paraformaldehyde (PFA), $\mathrm{pH} 9.5$, in borax buffer. After perfusion with the fixative, sciatic nerves were dissected out, postfixed for $2 \mathrm{~d}$, and placed overnight in a $4 \%$ PFA-borax $/ 10 \%$ sucrose solution until tissue processing. For the purpose of histological and immunohistochemical labeling, animals were perfused instead with cold PBS followed by $4 \%$ PFA, pH 7.4, in PBS. Sciatic nerves were postfixed for $1 \mathrm{~h}$ only and placed in a $\mathrm{PBS} / 10 \%$ sucrose solution until sectioning.

Sciatic nerves were cut longitudinally, except for the experiment in which axonal regeneration was studied (transverse sections were used for this purpose), using a cryostat (model CM3050S; Leica Microsystems, Richmond Hill, Ontario, Canada) set at a thickness of $14 \mu \mathrm{m}$. Sciatic nerve sections were collected directly onto slides that have a permanent positive-charged surface (Surgipath Canada, Winnipeg, Manitoba, Canada), separated into four different series of adjacent sections, and stored at $-20^{\circ} \mathrm{C}$.

\section{ISH}

ISH was performed to detect mRNAs coding for the following proinflammatory molecules: IL- $1 \beta$, MCP-1, tumor necrosis factor (TNF), interferon $\beta$ (IFN $\beta$ ), and inducible nitric oxide synthase (iNOS). These five proinflammatory molecules were chosen based on the following two reasons: (1) solid in vivo evidence demonstrating a functional role for IL- $1 \beta$, MCP-1, and TNF in stimulating WD in the injured nervous system (Liefner et al., 2000; Siebert et al., 2000; Perrin et al., 2005); and (2) evidence that activation of TLRs signaling through MyD88-independent pathways results in the expression of IFN-inducible genes such as IFN $\beta$ and $i N O S$ (Akira and Takeda, 2004) (to study the importance of MyD88independent TLR pathways in the early events leading to macrophage responses and WD). Radiolabeled cRNA probes were synthesized using full-length cDNAs cloned into expression vectors pCRII-TOPO (IL-1 $\beta$, IFN $\beta$ ), pGEM-1 (MCP-1), and pBluescript II SK + (TNF, iNOS) and the Riboprobe Combination System SP6/T7 (Promega, Madison, WI) and T3 RNA polymerase (Promega). Sequences chosen for probe synthesis were selected to match only the intended genes, as verified by BLAST (Basic Local Alignment Search Tool) analysis in GenBank. ISH was performed according to a previously described method (Pineau and Lacroix, 2007). All sections were prehybridized, hybridized, and posthybridized in parallel to equalize background intensity.

\section{Histology and immunohistochemistry}

One series of adjacent sections was stained with Luxol fast blue (LFB) to identify myelin, following our previously published protocol (Vallières et al., 2006). These sections were used to quantify myelin clearance in the degenerating sciatic nerve distal stump.

Immunohistochemistry was performed to detect the following antigens: (1) mouse CD68 using the monoclonal anti-CD68 antibody (to visualize activated macrophages/monocytes; Serotec, Raleigh, NC), (2) growth-associated protein-43 (GAP-43) using the polyclonal antiGAP-43 antibody (to visualize regenerating axons; Novus Biologicals, Littleton, CO), (3) rat CD68 using the monoclonal ED-1 antibody (to visualize activated macrophages/monocytes; Serotec), (4) ionized calcium-binding adaptor molecule 1 (iba1) using the polyclonal antiibal antibody (to visualize macrophages/monocytes; Wako Chemicals USA, Richmond, VA), and (5) mouse CD45 using the monoclonal antiCD45 antibody (to visualize leukocytes; BD PharMingen, Mississauga, Ontario, Canada). Multiple immunofluorescence labeling was performed as described previously (Pineau and Lacroix, 2007). Immunoperoxidase labeling was performed following our previously published protocol, with the exception of the step in which sections are incubated with hydrogen peroxide $\left(\mathrm{H}_{2} \mathrm{O}_{2}\right)$ to reduce activity of endogenous peroxidases (Vallières et al., 2006). In this study, the $\mathrm{H}_{2} \mathrm{O}_{2}$ quenching procedure was performed with $6 \% \mathrm{H}_{2} \mathrm{O}_{2}$ in methanol for $1 \mathrm{~h}$. All sections were stained in parallel to equalize the background intensity and the peroxidase reaction.

To further confirm the clearance of myelin debris and examine the myelin phagocytic activity of macrophages in our experiments, Oil red $\mathrm{O}$ (ORO) staining was combined with CD68 immunofluorescence on the same series of sciatic nerve sections. As reported previously by us and others, ORO staining is highly specific for degenerating myelin and for myelin that has been ingested by macrophages (Ma et al., 2002; Vallières et al., 2006). Immunofluorescence was performed first, followed by ORO staining. For ORO staining, sections were incubated in a $0.15 \%$ ORO/ $36 \%$ triethyl phosphate $/ 0.02 \%$ 4',6-diamidino-2-phenylindole solution for $20 \mathrm{~min}$, rinsed in TBS, and coverslipped with a glycerol-based aqueous mounting medium.

\section{Quantification of ISH signal and histological and immunohistochemical labeling}

Levels of IL- $1 \beta$ and MCP-1 mRNA were quantified in the peripheral nerve distal stump using nuclear emulsion-dipped slides. Signal intensity was quantified within predefined $1 \mathrm{~mm}$ sciatic nerve segments, starting from the site of injury (identified by the 10-0 suture node) up to $4 \mathrm{~mm}$ distal to the lesion. Thus, a total of four sciatic nerve segments were analyzed per animal ( $n=2-3$ sections per mouse). For each section analyzed, the outline of the longitudinal section was traced manually under bright-field illumination at $10 \times$ magnification. For the quantification, mean gray values (ranging from 0 to 255 bits) within this predefined area were measured under dark-field illumination using the Bioquant Nova Prime software (Bioquant Image Analysis Corporation, Nashville, TN) on video images of tissue sections transmitted by a highresolution Retiga QICAM fast color 1394 camera $(1392 \times 1040$ pixels; QImaging, Burnaby, British Columbia, Canada) installed on a Nikon (Tokyo, Japan) Eclipse 80i microscope. Mean gray values were corrected for the average background signal, which was measured in four boxes 25 $\mu \mathrm{m}$ high $\times 25 \mu \mathrm{m}$ wide placed in regions where a positive hybridization signal was absent. In addition, the number of cells expressing a positive mRNA signal was counted using our previously published method (Pineau and Lacroix, 2007). All data collection was done blind with respect to the identity of the animals.

For the quantification of activated macrophages (CD68) and macrophages that ingested myelin debris (CD68/ORO), the number of labeled cells was estimated by the optical fractionator method using the Bioquant Image software (Bioquant Image Analysis Corporation). First, the outline of the longitudinal segments were traced, as described above, and then sampled at $100 \times$ magnification. The counting parameters were as follows: sampling grid size, $225 \times 225 \mu \mathrm{m}$; counting frame size, $50 \times 50$ $\mu \mathrm{m}$; dissector height, $14 \mu \mathrm{m}$. Cells were counted only if their nuclei laid within the dissector area, did not intersect forbidden lines, and came into the focus as the optical plane moved through the height of the dissector.

For the quantification of myelin staining (LFB staining) and CD68 and ibal immunolabeling, the proportional area of tissue occupied by labeling within a region of interest was measured, as described previously (Vallières et al., 2006). Briefly, the outline of the longitudinal sections ( $n=3$ sections per mouse; $n=4$ sections per rat), starting from the site of injury up to $1.8 \mathrm{~mm}$ distal to the lesion, was traced manually at $4 \times$ magnification. The area of tissue occupied by the histochemical staining in this sampling area was then measured using the Bioquant Nova Prime software on video images transmitted by the Retiga camera. Thresholding values in Bioquant Image were chosen such that only a labeled prod- 
uct resulted in measurable pixels on the digitized image. Contrast between positive signal and background was maximized and held constant between all images. GAP-43 immunolabeling was quantified in transverse sciatic nerve sections at a distance of $4 \mathrm{~mm}$ distal to the lesion using the same method. A similar approach has been used by others to assess axonal regeneration in vivo (Krekoski et al., 2002; Pot et al., 2002).

\section{Real-time quantitative RT-PCR}

Total RNA was extracted from sciatic nerves (exsanguinated by intracardiac perfusion with saline) using the TRIzol method following the manufacturer's protocol (Invitrogen Canada, Burlington, Ontario, Canada). RNA quantity and quality were assessed using the RNA 6000 Nano LabChip and Agilent (Mountain View, CA) Bioanalyzer 2100. cDNA was generated from $40 \mathrm{ng}$ of total RNA using a random primer hexamer and following the protocol for Superscript II reverse transcriptase (Invitrogen Canada). Equal amounts of cDNA were amplified in a final volume of $15 \mu \mathrm{l}$ containing $7.5 \mu \mathrm{l}$ of $2 \times$ Universal PCR Master Mix (Applied Biosystems, Foster City, CA), $10 \mathrm{~nm}$ Z-tailed forward primer, $100 \mathrm{~nm}$ untailed reverse primer, $250 \mathrm{~nm}$ Amplifluor Uniprimer probe (Chemicon, Temecula, CA), and $5 \mu \mathrm{l}$ of cDNA $(20 \mathrm{ng} / \mu \mathrm{l})$. Primer pairs were identical to the ones used previously (Sergerie et al., 2007). Amplification was performed using the Applied Biosystems Prism 7900 Sequence Detector and the following conditions: $2 \mathrm{~min}$ at $50^{\circ} \mathrm{C}, 4 \mathrm{~min}$ at $95^{\circ} \mathrm{C}$, followed by 55 cycles of $15 \mathrm{~s}$ at $95^{\circ} \mathrm{C}$ and $30 \mathrm{~s}$ at $55^{\circ} \mathrm{C}$. Amplification efficiencies were validated and normalized to ribosomal $18 \mathrm{~S}$, and amounts of IL- $1 \beta$ mRNA levels were calculated according to a standard curve.

\section{Cytokine antibody array}

IL- $1 \beta$ protein levels after sciatic nerve lesion were analyzed in mice deficient in TLR signaling and their wild-type littermates using mouse antibody arrays (RayBio Mouse Inflammation Antibody Array 1; RayBiotech, Norcross, GA). Protein lysates were obtained by homogenization of sciatic nerve distal stumps collected from three mice per group (bilateral; $n=6$ nerves) in cell lysis buffer (included in the kit) following the manufacturer's protocol. Protein concentration was determined by using the bicinchoninic acid kit (Sigma-Aldrich Canada). A total of $375 \mu \mathrm{g}$ of protein was incubated with each array membrane overnight at $4^{\circ} \mathrm{C}$. The membranes were then processed according to the RayBiotech protocol, exposed to $\mathrm{x}$-ray films (Eastman Kodak, Rochester, NY), and analyzed using ImageJ software (version 1.23; National Institutes of Health, Bethesda, MD). As recommended by the manufacturer, integrated optical density (I.O.D) values generated from sciatic nerve lysates of naive mice (i.e., negative controls) were subtracted from I.O.D values obtained from lesioned animals, to generate relative cytokine levels after injury.

\section{Behavioral analyses}

Recovery of locomotor function after sciatic nerve lesion was quantified using the sciatic nerve functional index (SFI). This test was performed for all animals preoperatively and every week for 7 weeks after the operation. To assess hindlimb performance, each animal was put on a scanner connected to a computer-assisted system, and at least three digitized images of the paws were taken. The SFI was measured from these images, using the formula developed by Bain et al. (1989) for rats and the formula adapted for mice by Inserra et al. (1998). Measurements were taken from the control and operated sides of each animal using the ImageJ software. SFI values oscillated around $0 \pm 10$ for noninjured animals and around $\sim 100 \pm 10$ after complete lesion of the sciatic nerve (de Medinaceli et al., 1982).

\section{Statistical analyses}

For each individual group of animals included in experiments that required behavioral analyses, differences between SFI values before and after nerve injury were compared using an ANOVA. Post hoc comparisons were made using the Bonferroni test to determine at which time point the animals had recovered sciatic functions equivalent to their baseline performances. Statistical comparisons of SFI values between groups and cytokine/chemokine ISH signal and CD68 immunolabeling at various distances from the site of injury were made using two-way repeated-measures ANOVA followed by the Bonferroni test. Significance for GAP-43 immunolabeling was analyzed using Student's $t$ test. A two- factor ANOVA comparison without repeated measures was used for the statistical comparison of all other data. Post-ANOVA comparisons were once again made using the Bonferroni test. All statistical analyses were performed using the GraphPad Prism software (GraphPad Software, San Diego, CA). A $p$ value $<0.05$ was considered as statistically significant. Data in graphs are presented as mean \pm SEM.

\section{Results \\ Experiment 1: effects of TLR signaling deficiency on the lesioned sciatic nerve}

TLR signaling regulates early expression of IL-1 $\beta$ and MCP-1

Using ISH, we first examined the relative expression levels for mRNAs encoding inflammatory molecules in the sciatic nerve distal stump of TLR2-, TLR4-, and MyD88-deficient mice. For this experiment, mice were killed at 1.5 and $24 \mathrm{~h}$ after lesion. These two time points were selected based on a previous study, which showed that MCP-1 mRNA is already expressed at $1.5 \mathrm{~h}$ after sciatic nerve lesion, with maximal expression occurring at $24 \mathrm{~h}$ (Carroll and Frohnert, 1998). As expected, we found no hybridization signal for any of the proinflammatory molecules analyzed (i.e., IL- $1 \beta$, MCP-1, TNF, IFN $\beta$, and iNOS) on sciatic nerve sections obtained from noninjured mice. This was obviously not the case after a sciatic nerve lesion. At $1.5 \mathrm{~h}$ after lesion, cells expressing IL- $1 \beta$ could already be detected, although in limited numbers, throughout the entire $10 \mathrm{~mm}$-long sciatic nerve segments analyzed (these segments included $5 \mathrm{~mm}$ on each side of the lesion) (Fig. 1A). By $24 \mathrm{~h}$, the number of cells expressing IL-1 $\beta$ mRNA in the sciatic nerve distal stump of C57BL/6J had increased by more than eightfold compared with the $1.5 \mathrm{~h}$ time point, passing from $78 \pm 10$ to $662 \pm 84$ cells $/ \mathrm{mm}^{2}$ (Fig. $1 D$ ). IL-1 $\beta$ mRNA expression was preferentially increased in areas located near the lesion site (Fig. $1 F$ ), therefore confirming results obtained by RNase protection assays in a previous study (Perrin et al., 2005). In contrast, very few IL- $1 \beta^{+}$cells could be seen at any of these two time points in MyD88-ko mice (Fig. $1 B, E$ ), with the following numbers: $6 \pm 5$ cells $/ \mathrm{mm}^{2}$ at $1.5 \mathrm{~h}$ and $43 \pm 13$ cells $/ \mathrm{mm}^{2}$ at $24 \mathrm{~h}$. A significant difference in IL- $1 \beta$ mRNA levels was also detected between TLR2-ko mice and their wild-type littermates at $24 \mathrm{~h}$ after lesion (Fig. $1 F$ ). To confirm the differential expression of IL- $1 \beta$ mRNA in mice deficient in TLR signaling compared with control groups, real-time quantitative RT-PCR (qRT-PCR) experiments were performed on total RNA extracted from sciatic nerve distal stumps at $24 \mathrm{~h}$ after lesion. Results obtained by qRT-PCR confirmed ISH data and even extended these results by highlighting a significant twofold decrease in IL- $1 \beta$ mRNA levels in TLR4-deficient $\left(\mathrm{TLR} 4^{\mathrm{d}}\right.$ ) mice compared with their wild-type littermates (i.e., $\mathrm{C} 3 \mathrm{H} / \mathrm{HeOUJ}$ mice) (Fig. $1 G$ ). Importantly, IL-1 $\beta$ protein levels, as detected by cytokine antibody arrays, paralleled the transcriptional changes observed by ISH and qRT-PCR (Fig. $1 H$ ), therefore strengthening our results showing that early expression of IL- $1 \beta$ is compromised in the sciatic nerve distal stump of mice deficient in TLR signaling.

As for IL- $1 \beta$, cells expressing MCP- 1 mRNA could also be detected as early as $1.5 \mathrm{~h}$ after lesion (Fig. $2 \mathrm{~A}$ ). Once again, cells were seen along the entire nerve segment analyzed. By $24 \mathrm{~h}$ after lesion, the number of $\mathrm{MCP}-1^{+}$cells found in the sciatic nerve distal stump of C57BL/6J mice had almost doubled (Fig. 2D), increasing from $615 \pm 44$ to $1153 \pm 41 \mathrm{cells} / \mathrm{mm}^{2}$. Quantitative analyses of ISH for MCP-1 mRNA revealed that signal was significantly weaker in the sciatic nerve distal stump of MyD88-ko mice compared with wild-type littermates at 1.5 and $24 \mathrm{~h}$ after lesion (Fig. $2 B, C, E, F$ ). Together, these results provide direct evidence that early production of IL- $1 \beta$ in lesioned peripheral nerves is regulated through MyD88-dependent signaling path- 


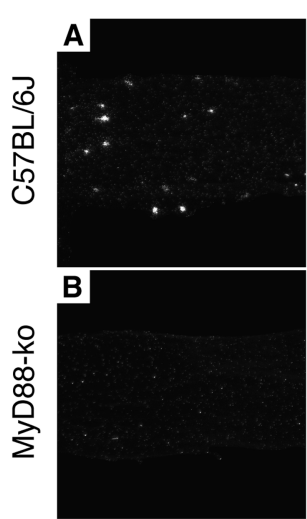

$1.5 \mathrm{hrs}$

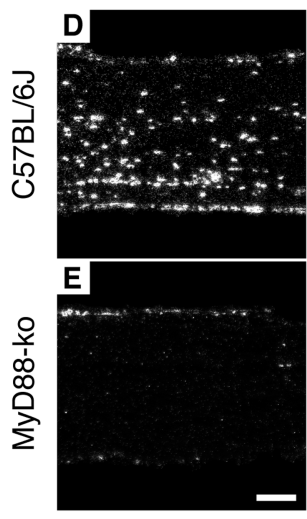

$24 \mathrm{hrs}$
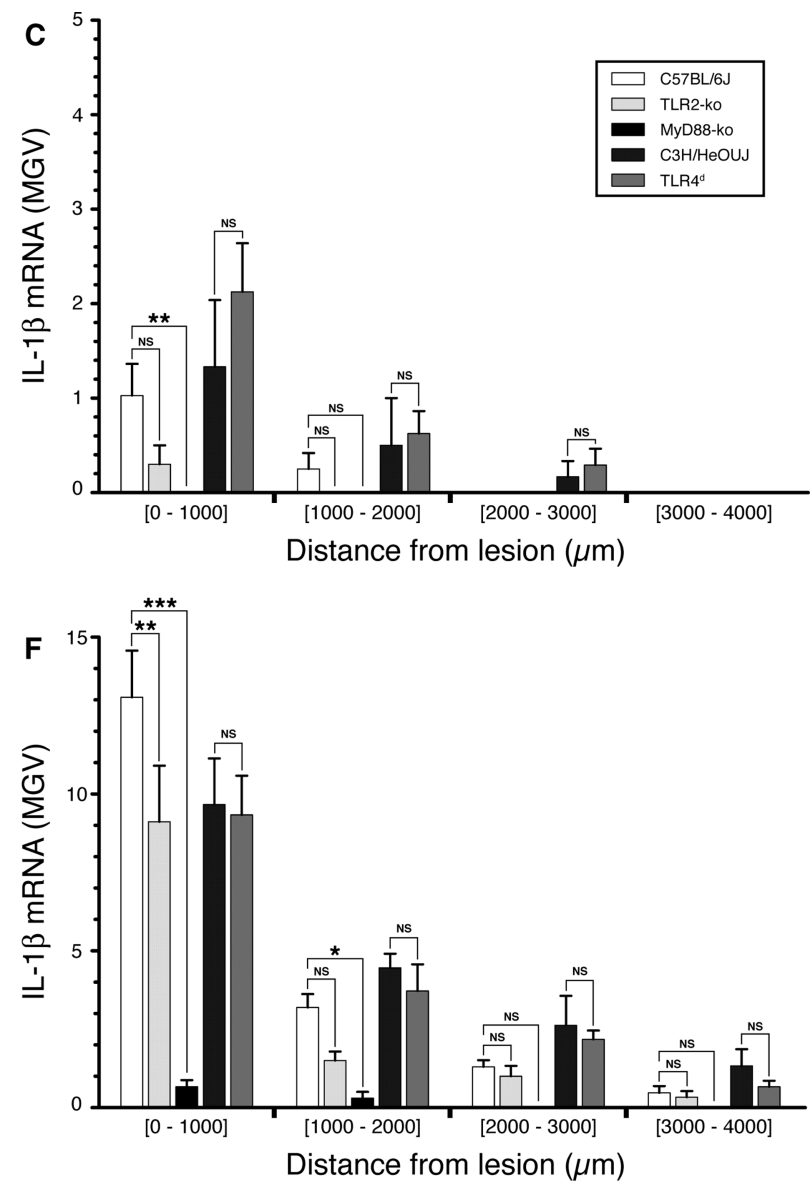

G

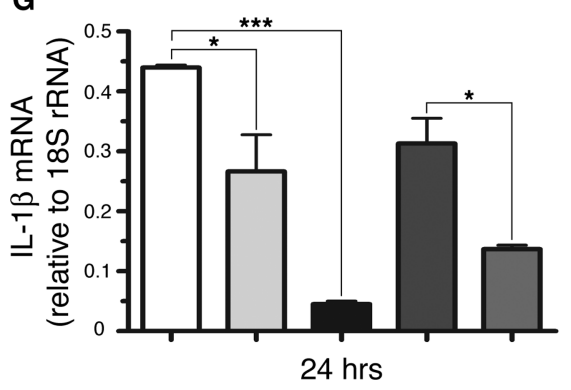

H

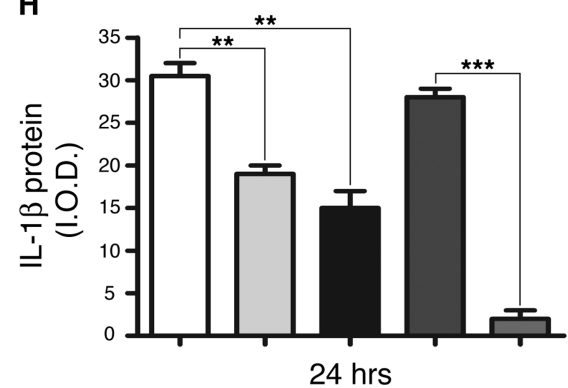

Figure 1. Early expression of IL-1 $\beta$ is abolished in the sciatic nerve distal stump of mice deficient in TLR signaling. $A, B, D, E$, Representative dark-field photomicrographs showing IL-1 $\beta$ mRNA expression in C57BL/6J $(\boldsymbol{A}, \boldsymbol{D})$ and MyD88-ko $(\boldsymbol{B}, \boldsymbol{E})$ mice at $1.5 \mathrm{~h}(\boldsymbol{A}, \boldsymbol{B})$ and $24 \mathrm{~h}(\boldsymbol{D}, \boldsymbol{E})$ after sciatic nerve lesion. All photomicrographs were taken at the same level of the sciatic nerve distal stump. $C, F$, Quantification of ISH signal for IL-1 $\beta$ mRNA [in mean gray values (MGV)] in the sciatic nerve distal stump of TLR2-ko, MyD88-ko, and TLR4 ${ }^{\mathrm{d}}$ mice and their respective wild-type littermates at $1.5 \mathrm{~h}(\boldsymbol{C})$ and $24 \mathrm{~h}(\boldsymbol{F})$ after lesion $(n=4-6$ per group per time point). G, qRT-PCR analyses confirmed that IL-1 $\beta$ expression is severely compromised in TLR2-, TLR4-, and MyD88-deficient mice at $24 \mathrm{~h}$ after sciatic nerve lesion ( $n=3-5$ per group). Data are expressed as the ratio to 185 ribosomal RNA (rRNA). $\boldsymbol{H}$, Protein levels for IL-1 $\beta$, as detected using cytokine arrays and expressed as I.0.D., are significantly reduced in TLR2-, TLR4-, and MyD88deficient mice compared with their respective wild-type littermates at $24 \mathrm{~h}$ after sciatic nerve lesion ( $n=3$ per group). All data are expressed as mean \pm SEM. Statistical significance bars were added to graphs to more directly infer whether any two means are statistically significant from one another. ${ }^{* * *} p<0.001,{ }^{* *} p<0.01$, and ${ }^{*} p<0.05$ compared with the control group. NS, Not statistically significant. Scale bar, $125 \mu \mathrm{m}$.

ways, whereas MCP-1 expression is partly controlled by MyD88 signaling.

In contrast to IL- $1 \beta$ and MCP-1, TNF mRNA was barely expressed in injured peripheral nerves. Occasionally, a few scattered $\mathrm{TNF}^{+}$cells were seen throughout the nerve at $1.5 \mathrm{~h}$, whereas they were mostly associated with the epineurium located at the level of the lesion site at $24 \mathrm{~h}$ (data not shown). These results do not rule out the possibility that more significant levels of TNF could have been detected at later time points after injury. In this regard, others have reported, using a similar lesion model, that TNF expression in the rodent sciatic nerve distal stump peaks at 3 d after injury (La Fleur et al., 1996; George et al., 2004; Sawada et al., 2007). The hybridization signal for the genes encoding IFN $\beta$ and iNOS mRNA was comparable to background levels (data not shown). Because of the limited or lack of expression of these transcripts in injured sciatic nerves, the quantification was not possible for TNF, IFN $\beta$, and iNOS.

TLRs regulate macrophage recruitment and/or activation and myelin debris clearance during WD

Macrophages respond to various chemotactic and stimulatory signals that help orchestrate and control immune responses, including chemokines and cytokines released at the site of nerve injury. Thus, we next examined whether recruitment and/or activation of macrophages would be reduced after sciatic nerve lesion in various strains of mice deficient in TLR signaling. This was done by visualizing a cellsurface antigen expressed by activated macrophages, CD68, using immunofluorescence. As shown in Figure $3 A-E$, the number of CD68-immunolabeled macrophages in the sciatic nerve distal stump was significantly reduced in TLR2-ko, TLR4 ${ }^{\mathrm{d}}$, and MyD88-ko mice compared with their respective wild-type littermates at $7 \mathrm{~d}$ after lesion. These results were confirmed by another method of quantification in which the proportional area of tissue occupied by CD68 immunofluorescence, rather than the number of $\mathrm{CD} 68^{+}$ cells, was measured in the sciatic nerve distal stump (data not shown). These results indicate that fewer macrophages were present in the sciatic nerve distal stump of mice deficient in TLR signaling, although the possibility remains that only the levels of expression of CD68 fluctuated. Activation of macrophages has been reported by others to lead to the upregulation of certain receptors, including CD68 (Choucair et al., 2006).

Macrophages are the principal type of leukocytes found in peripheral nerves after injury and contribute, at least in part, to myelin debris clearance during WD (Beuche and Friede, 1984; Stoll et al., 1989; Bruck et al., 1996). We therefore investigated whether clearance of myelin debris would be delayed in the absence of TLR signaling. Quantification of LFB staining, a marker of myelin, in the sciatic nerve distal stump revealed that the load of myelin debris was 70, 300, and $60 \%$ higher in TLR2-ko, TLR4 ${ }^{\mathrm{d}}$, and MyD88-ko mice, respectively, 
compared with their wild-type littermates at $7 \mathrm{~d}$ after injury (Fig. $3 F-J$ ). Examination and quantification of myelin clearance on LFB-stained sections has been successfully and repeatedly performed by several groups of experts working in the regeneration and multiple sclerosis fields (Noble and Wrathall, 1989; Behrmann et al., 1992; Basso et al., 1996; Liu et al., 1998; Popovich et al., 1999; Ma et al., 2001, 2002; Karnezis et al., 2004). Results published by some of these groups have demonstrated that the amount of white matter loss measured with LFB correlates very well with the degree of functional loss observed after injury/disease. These studies have also shown that white matter areas where LFB staining is reduced normally correspond to the areas infiltrated by immune cells and show increased ORO staining, a marker for degenerating myelin and myelin ingested by immune cells. Together, these results indicate that TLR signaling is important for macrophage recruitment/activation and clearance of myelin debris during WD.

\section{Axonal regeneration and recovery of locomotor function are delayed in the absence of TLR signaling}

In the injured nervous system, axonal regeneration is limited by several proteins associated with myelin (David and Lacroix, 2003). After peripheral nerve injury, these inhibitors, which become exposed as a result of damage to axons and myelin sheaths, are rapidly removed by macrophages and Schwann cells, and regeneration can proceed. To address whether nerve regeneration would be affected by a deficiency in TLR signaling, which we have previously found to reduce macrophage and leukocyte infiltration/activation and significantly delay clearance of myelin and its inhibitors, we assessed axonal regeneration in the sciatic nerve distal stump of C57BL/6J and MyD88-ko mice at $4 \mathrm{~d}$ after injury. Axonal regeneration was assessed by GAP-43 immunofluorescence using transverse sciatic nerve sections taken at a distance of $4 \mathrm{~mm}$ distal to the lesion. Quantification of GAP-43 immunolabeling revealed the presence of a significantly smaller number of regenerating sciatic nerve axons in MyD88-ko mice compared with wild-type littermates, indicating slower regeneration in mice deficient in TLR signaling. Thus, we next examined recovery of locomotor function in our animals using the SFI (Fig. $3 L, M)$. Results showed no statistically significant difference in the preoperative SFI values among the five different groups included in this experiment. When compared with their respective wild-type controls, statistical significance for SFI values of TLR2-ko, TLR4 ${ }^{\mathrm{d}}$, MyD88-ko mice was reached at four different time points (i.e., 7, 14, 21 , and $28 \mathrm{~d}$ after injury). Whether compensation by sprouting of axons that were spared by the crush injury may be responsible for the behavioral differences observed between mouse strains at $7 \mathrm{~d}$ cannot be excluded based on this study. A significant difference was also detected at day 35 for MyD88-ko mice relative to wild-type littermates, indicating a temporarily limited effect. In agreement with previous studies, $\mathrm{C} 57 \mathrm{BL} / 6 \mathrm{~J}$ and $\mathrm{C} 3 \mathrm{H} / \mathrm{HeOUJ}$ mice (i.e., control
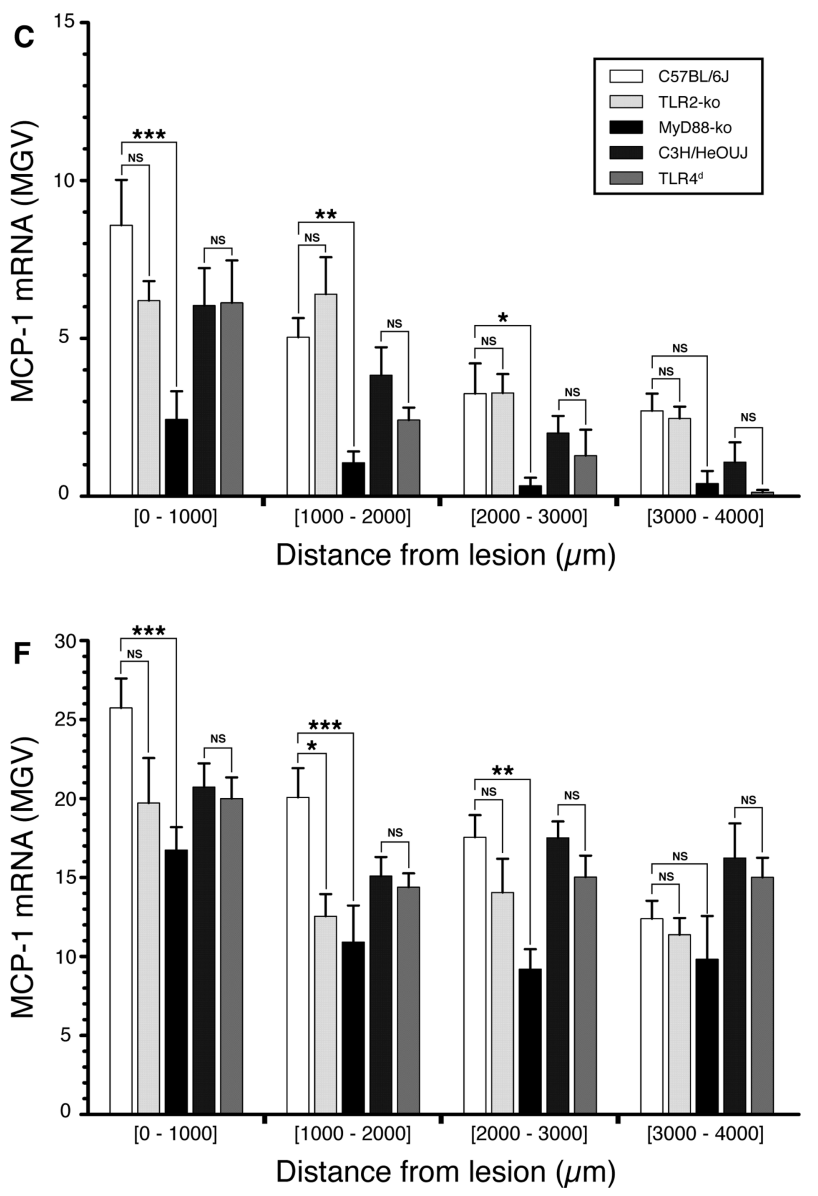

Figure 2. Early expression of $M C P-1$ is compromised in the sciatic nerve distal stump of mice deficient in TLR signaling. $A, B, D$, $\boldsymbol{E}$, Representative dark-field photomicrographs showing expression for MCP-1 mRNA in C57BL/6J $(\boldsymbol{A}, \boldsymbol{D})$ and MyD88-ko $(\boldsymbol{B}, \boldsymbol{E})$ mice at $1.5 \mathrm{~h}(\boldsymbol{A}, \boldsymbol{B})$ and $24 \mathrm{~h}(\boldsymbol{D}, \boldsymbol{E})$ after sciatic nerve lesion. All photomicrographs were taken at the same level of the sciatic nerve distal sump. $C, F$, Quantification of ISH signal for MCP-1 mRNA [in mean gray values (MGV)] in the sciatic nerve distal stump of TLR2-ko, MyD88-ko, and TLR4 ${ }^{d}$ mice and their respective wild-type littermates at $1.5 \mathrm{~h}(\boldsymbol{C})$ and $24 \mathrm{~h}(\boldsymbol{F})$ after lesion $(n=4-6$ per group per time point). All data are expressed as mean \pm SEM. ${ }^{* * *} p<0.001,{ }^{* *} p<0.01$, and ${ }^{*} p<0.05$ compared with the control group. NS, Not statistically significant. Scale bar, $125 \mu \mathrm{m}$.

groups) had recovered sciatic functions equivalent to their presurgical performances $(p>0.05)$ by 21 and $28 \mathrm{~d}$ after lesion, respectively (Inserra et al., 2000; Pot et al., 2002). In contrast, recovery of hindlimb function was only attained at day 35 for TLR2-ko and TLR4 ${ }^{\mathrm{d}}$ mice and at day 42 for MyD88-ko mice. This suggests that TLR signaling is involved in recovery of hindlimb motor and sensory function after peripheral nerve injury.

Experiment 2: effects of intraneural delivery of TLR ligands on the unlesioned and lesioned sciatic nerve Injection of TLR2 and TLR4 ligands accelerates phagocytosis of myelin debris during WD

To confirm the hypothesis that activation of TLR2 and TLR4 is involved in leukocyte recruitment/activation and myelin debris clearance after sciatic nerve injury, as opposed to the required presence of these two receptors for signaling by other receptor complexes, we performed a second set of experiments in which we microinjected TLR2 and TLR4 ligands in the intact sciatic nerve or at the site of sciatic nerve lesion. These experiments were conducted in rats instead of mice to minimize the extent of the damage that could have been inflicted during the microinjection procedure. First, we sought to determine whether a single injection of TLR 2 and TLR4 ligands into the sciatic nerve of uninjured rats would stimulate the expression of IL- $1 \beta$ and MCP- 1 and the 

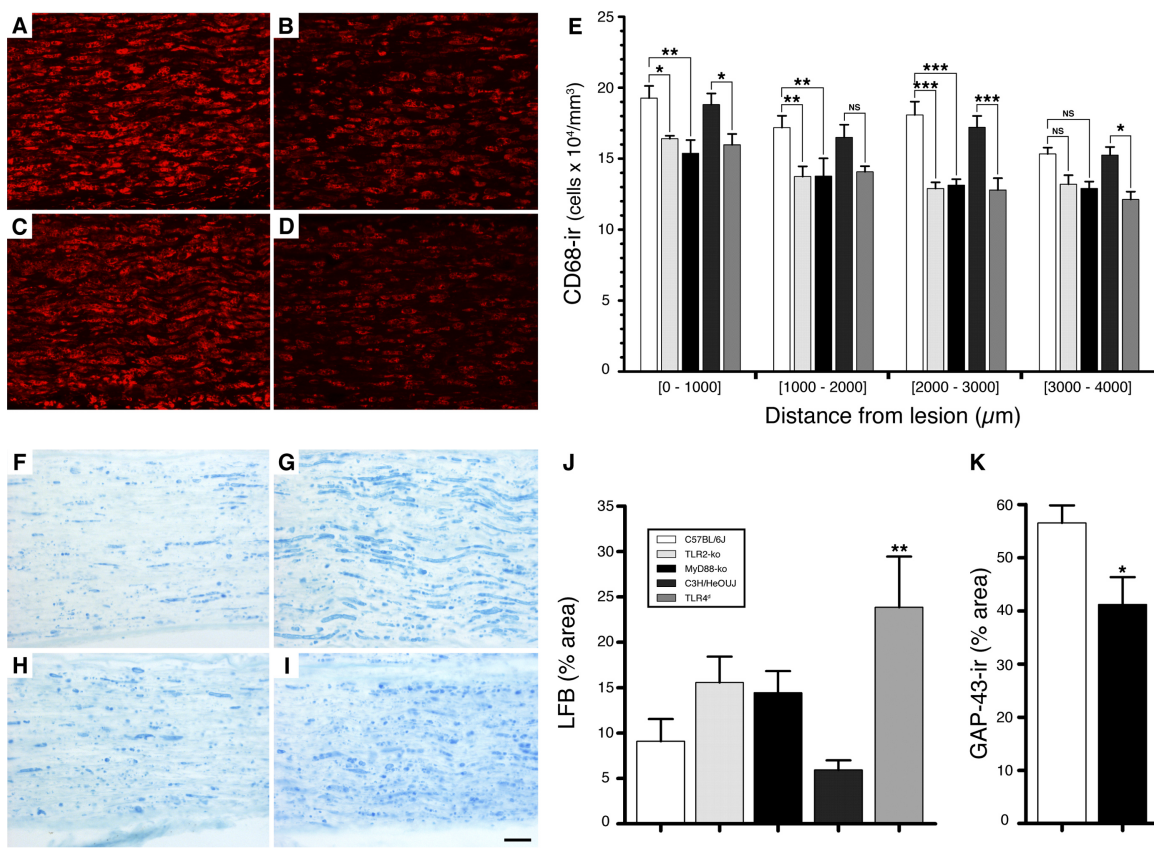

$\mathbf{J}$

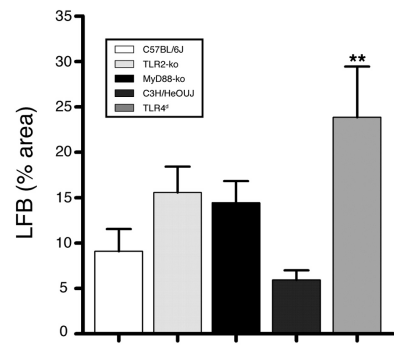

$\mathbf{K}$

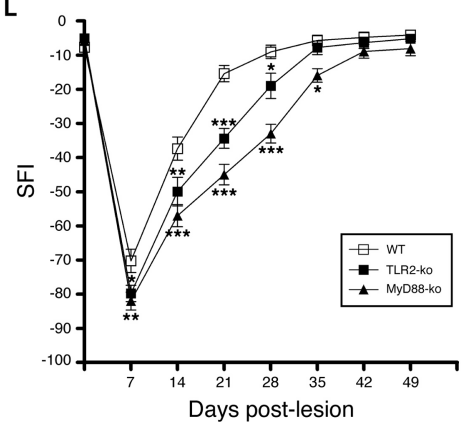

M

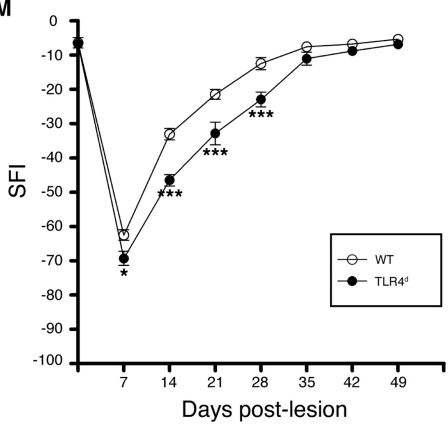

Figure 3. Deficiency in TLR signaling compromises macrophage recruitment/activation and delays myelin debris clearance, axonal regeneration, and locomotor recovery after sciatic nerve lesion. $\boldsymbol{A}-\boldsymbol{D}$, Representative fluorescence photomicrographs taken from longitudinal sections of the sciatic nerve distal to the lesion showing CD68-immunopositive macrophages in $C 57 \mathrm{BL} / 6 \mathrm{~J}$ $(\boldsymbol{A})$, TLR2-ko $(\boldsymbol{B}), \mathrm{C} 3 \mathrm{H} / \mathrm{HeOUJ}(\boldsymbol{C})$, and TLR4 ${ }^{\mathrm{d}}(\boldsymbol{D})$ mice at $7 \mathrm{~d}$. $\boldsymbol{E}$, Quantification of the number of CD68 ${ }^{+}$macrophages in the sciatic nerve distal stump of TLR2-ko, TLR4 ${ }^{\mathrm{d}}$, MyD88-ko, and wild-type mice at $7 \mathrm{~d}$ after lesion ( $n=8$ per group). $\boldsymbol{F}$-I, Bright-field photomicrographs showing myelin stained with LFB in the sciatic nerve distal stump of $\mathrm{C57BL} / 6 \mathrm{~J}(\boldsymbol{F}), \mathrm{TLR2}-\mathrm{ko}(\boldsymbol{G}), \mathrm{C3H} / \mathrm{HeOUJ}(\boldsymbol{H})$, and TLR4 ${ }^{\mathrm{d}}(\boldsymbol{I})$ mice at $7 \mathrm{~d}$. $J$, Quantification of LFB staining of myelin in the degenerating sciatic nerve distal stump of mice deficient in TLR signaling at $7 \mathrm{~d}(n=8$ per group). $\boldsymbol{K}$, Quantification of the number of axons that had regenerated up to $4 \mathrm{~mm}$ distal to the site of lesion, as visualized by GAP-43 immunofluorescence, at $4 \mathrm{~d}$ after lesion. $\boldsymbol{L}, \boldsymbol{M}$, Recovery of locomotor functions from a sciatic nerve lesion, as determined by the SFI, in TLR2-k0,MyD88-ko, and TLR4 ${ }^{\mathrm{d}}$ mice compared with their respective control groups (WT) over a period of $49 \mathrm{~d}$ ( $n=12$ per group). ${ }^{* * *} p<$ $0.001,{ }^{* *} p<0.01$, and ${ }^{*} p<0.05$ compared with the control group. Scale bar, $50 \mu \mathrm{m}$.

recruitment/activation of leukocytes. Not surprisingly, very few cells expressing the IL-1 $\beta$ and MCP- 1 hybridization signal could be seen in PBS-injected rats (these cells were mostly associated with the epineurium) (see supplemental Fig. $1 A, C$, available at www.jneurosci.org as supplemental material). In contrast, a single microinjection of zymosan or LPS was sufficient to stimulate robust IL- $1 \beta$ and MCP-1 synthesis in intact sciatic nerves as early as $1.5 \mathrm{~h}$ after injection (supplemental Fig. $1 B, D$, available at www. jneurosci.org as supplemental material). Interestingly, the distribution of cells expressing IL- $1 \beta$ and MCP- 1 and the intensity of signal within these cells mimicked the expression pattern observed after sciatic nerve lesion in mice. At day 3 after injection (still no lesion), leukocytes had densely infiltrated the nerves of zymosan- and LPSinjected rats, whereas only a few sporadic $\mathrm{CD} 45^{+}$cells could be seen in PBS-treated control animals (supplemental Fig. 1 E, F, available at www.jneurosci.org as supplemental material).
We next examined the impact of injecting TLR2 and TLR4 ligands on the clearance of myelin debris in the context of a sciatic nerve lesion. To accomplish this, we first established that more macrophages, as visualized by CD68 and iba 1 immunofluorescence, were infiltrating the nerves of zymosan- and LPS-injected rats after injury (Fig. $4 A-C$ ). Multiple fluorescence labeling techniques and stereological methods were then used to quantify the number of macrophages that had phagocytosed myelin debris. This was performed on sciatic nerve sections that were immunolabeled with ibal and then stained with ORO, which has a very high affinity for degenerating myelin and myelin that has been ingested by macrophages (for examples of double-labeled cells, see Fig. 4D,E). Three days after injection of TLR ligands, quantitative analyses revealed that the number of macrophages that had ingested myelin debris was increased by 155 and $210 \%$ in zymosan- and LPSinjected rats, respectively, compared with PBS-injected rats, suggesting a greater clearance of myelin debris in these lesioned animals. Quantification of LFB staining of myelin confirmed that rats given an injection of zymosan or LPS had less myelin debris in their sciatic nerve distal stump compared with controls at $7 \mathrm{~d}$ after lesion/treatment (Fig. $4 G$ ), indicating that activation of TLR2 and TLR4 contributes to myelin debris clearance during WD.

\section{Injection of TLR 2 and TLR4 ligands} accelerates recovery of locomotor function As in experiment 1 , we next investigated the effects of injecting TLR2 and TLR4 ligands at the site of lesion on peripheral nerve recovery using the SFI. Compared with PBS-injected rats, animals that received zymosan or LPS showed a statistically significant improvement in locomotor behavior at 14, 21, and $28 \mathrm{~d}$ after lesion (Fig. $4 H$ ). Notably, LPS-treated rats had recovered sciatic functions equivalent to their presurgical performances $(p>0.05)$ by $21 \mathrm{~d}$, which is 2 weeks faster than PBS-injected animals.

\section{Experiment 3: effects of glucocorticoid treatment on the lesioned sciatic nerve}

Treatment with glucocorticoid agents reduces macrophage recruitment and/or activation and myelin debris clearance during WD

Glucocorticoids are the most powerful endogenous inhibitors of innate immune responses, because they can directly interfere with the transcriptional activation of NF-kB and its partners (Glezer and Rivest, 2004; Sternberg, 2006). This explains why agents such as DEX and MP are still widely used to treat traumatic spinal cord and nerve injuries (David and Lacroix, 2005; Steinsapir, 2006). However, as demonstrated in the present study, the 
immune response that rapidly develops after nerve injury is essential to support the healing/regenerative process. Thus, we next investigated whether acute treatment with synthetic glucocorticoids would alter macrophage responses and clearance of inhibitory myelin debris after sciatic nerve lesion in rats. At $7 \mathrm{~d}$ after lesion, we found a significant decrease in levels of CD68 immunoreactivity in the sciatic nerve distal stump of DEX-treated animals compared with saline-treated controls (Fig. 5A). However, there was no significant difference in proportional area occupied by CD68 immunolabeling in MP-treated rats compared with controls. LFB staining of myelin showed that rats treated with DEX had three times more myelin debris in their sciatic nerve distal stump than salinetreated rats at $7 \mathrm{~d}$ after lesion $(p<0.001$, ANOVA) (Fig. $5 B, C$ ). In MP-treated rats, the load of myelin debris was $75 \%$ higher than in saline-treated animals, although this difference did not reach statistical significance. Together, these results indicate that acute treatment with synthetic glucocorticoids compromises posttraumatic inflammation, which results in significant delays in the onset of WD.

\section{Glucocorticoid-mediated alteration of immune responses delays recovery of locomotor function}

To test the influence of glucocorticoid treatment on peripheral nerve regeneration, neurological recovery was assessed in DEX-and MP-treated rats at various time points after sciatic nerve lesion using the SFI. Saline-treated rats recovered in $28 \mathrm{~d}$ (Fig. 5D), in line with published data (de Medinaceli et al., 1982). In contrast, MPtreated rats needed $42 \mathrm{~d}$ to recover sciatic nerve functions, whereas DEX-treated animals never completely recovered sciatic functions equivalent to their presurgical performances at any of the time points analyzed in this study (Fig. 5D). Animals given injections of DEX exhibited significantly larger locomotor deficits than those in the control group at 7, 14, and $21 \mathrm{~d}$ after lesion. From these results, we can conclude that delayed WD in sciatic nerves of glucocorticoid-treated rats is associated with delayed regeneration and functional recovery.

\section{Discussion}

This is the first in vivo study to demonstrate that activation of innate immune responses through TLRs is important for WD, axonal regeneration, and recovery of locomotor functions after peripheral nerve injury. Specifically, we showed that early expression of the proinflammatory molecules IL- $1 \beta$ and MCP- 1 is compromised in TLR2-, TLR4-, and MyD88-deficient mice compared with their wild-type littermates. Deficiency in TLR
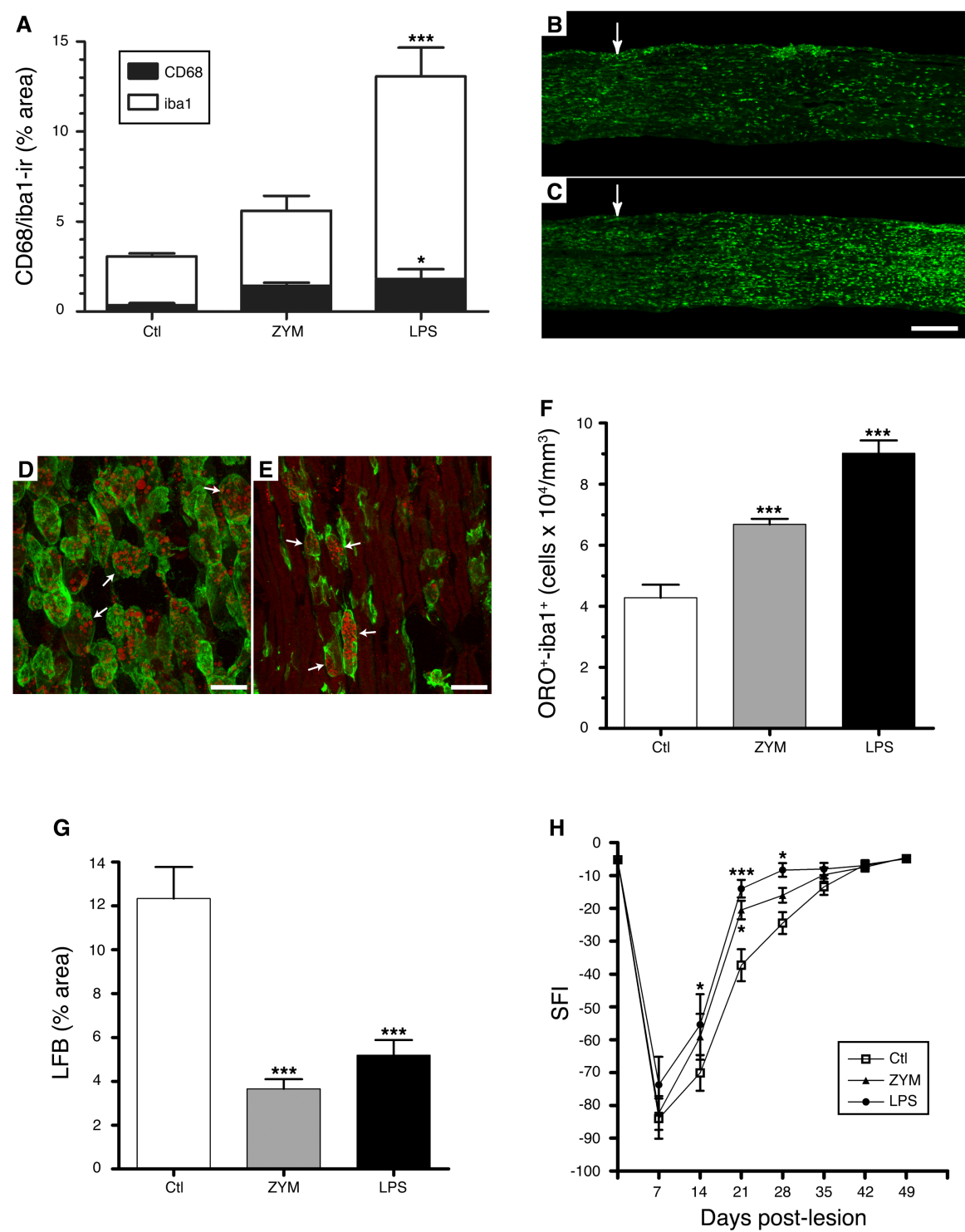

Figure 4. Activation of TLR signaling through intraneural injections of TLR2 and TLR4 ligands enhances the recruitment and myelin phagocytic activity of macrophages and accelerates myelin debris clearance and locomotor recovery after sciatic nerve lesion. $A$, Quantification of CD68 and iba1immunoreactivity (ir) in the degenerating sciatic nerve distal stump of rats that received a single microinjection of PBS (Ctl), zymosan (ZYM; a TLR2 ligand), or LPS (a TLR4 ligand) at the site of lesion (3 d time point; $n=$ 8 per group). $\boldsymbol{B}, \boldsymbol{C}$, Representative fluorescence photomicrographs showing iba1-immunopositive macrophages in a PBS-injected $(\boldsymbol{B})$ and a LPS-injected $(\boldsymbol{C})$ rat. Arrows indicate the lesion epicenter. $\boldsymbol{D}, \boldsymbol{E}$, Confocal high-power photomicrographs showing examples of iba ${ }^{+}$macrophages (green) that have ingested myelin debris (red), as detected using the 0 RO staining. Arrows point to double-labeled cells. $\boldsymbol{F}$, Quantification of the number of macrophages that have ingested myelin debris in the sciatic nerve distal stump of rats treated with PBS, ZYM, or LPS at $3 \mathrm{~d}$ after lesion per injection ( $n=8$ per group). G, Quantification of LFB staining of myelin in the degenerating sciatic nerve distal stump at $7 \mathrm{~d}$ ( $n=6-7$ per group). $\boldsymbol{H}$, Recovery of locomotor functions from a sciatic nerve lesion in rats given microinjections of PBS or TLR ligands ( $n=10$ per group). ${ }^{* * *} p<0.001$ and ${ }^{*} p<0.05$ compared with the Ctl group. Scale bars: $B, C, 260 \mu \mathrm{m} ; \boldsymbol{D}, 8.5 \mu \mathrm{m} ; \boldsymbol{E}, 14 \mu \mathrm{m}$.

signaling also resulted in the recruitment/activation of significantly fewer macrophages, persistence of myelin debris in the degenerating sciatic nerve distal stump, and important delays in axonal regeneration and recovery of hindlimb sensory and motor functions. In contrast, injections of TLR2 and TLR4 ligands at the site of sciatic nerve lesion accelerated myelin debris clearance and recovery of locomotor functions. Finally, treatment with synthetic glucocorticoids hindered macrophage responses, resulting in significant delays in clearance of degenerating myelin and functional recovery.

MyD88 is a critical adaptor protein mediating NF- $\kappa$ B signal- 

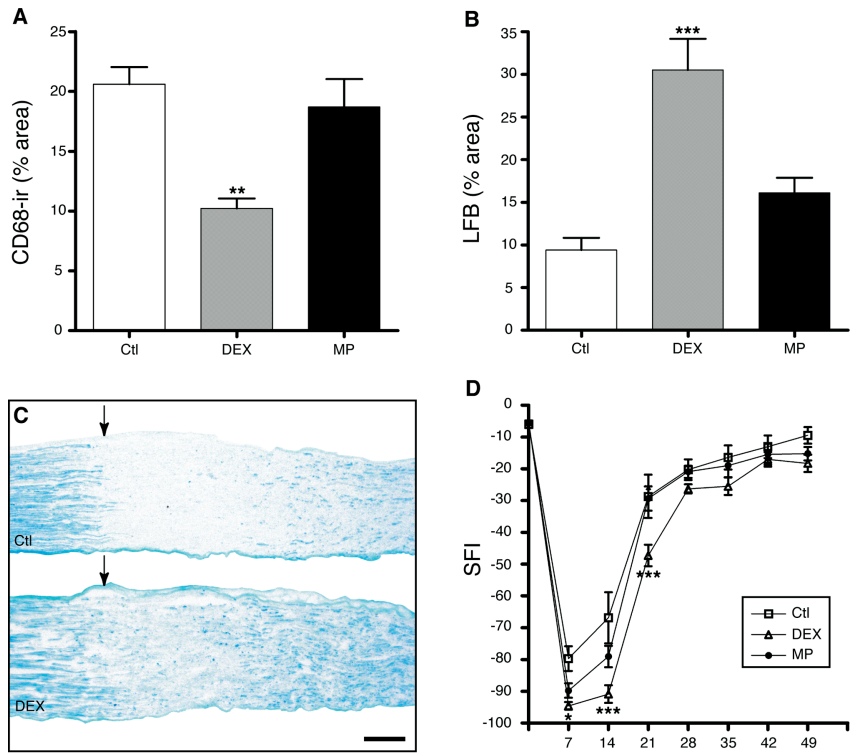

Days post-lesion

Figure 5. Alteration of immune responses by glucocorticoid treatment delays myelin debris clearance and recovery of locomotor functions after sciatic nerve lesion. $A$, Quantification of the recruitment/activation of $\mathrm{CD} 68{ }^{+}$macrophages in the sciatic nerve distal stump of rats treated with DEX, MP, or saline (Ctl) at $7 \mathrm{~d}$ after sciatic nerve lesion ( $n=5-6$ per group). $B$, Quantification of LFB staining of myelin in the degenerating sciatic nerve distal stump of rats treated with glucocorticoid agents or saline at $7 \mathrm{~d}(n=5-6$ per group). C, Bright-field photomicrographs showing myelin debris stained with LFB in the sciatic nerve of saline- and DEX-treated rats at $7 \mathrm{~d}$ after lesion. Arrows indicate the lesion site. $D$, Recovery of locomotor functions from a sciatic nerve lesion, as determined by the SFI, in rats treated with DEX, MP, or saline ( $n=$ $10-11$ per group). ${ }^{* * *} p<0.001,{ }^{* *} p<0.01$, and ${ }^{*} p<0.05$ compared with the Ctl group. Scale bar, $260 \mu \mathrm{m}$.

ing and transcriptional activation of a large family of proinflammatory molecules (Akira and Takeda, 2004). In particular, the MyD88 pathway is used when TLRs bind PAMPs, such as zymosan and LPS. Interestingly, our results show that this signaling pathway is essential for modulating innate immune responses after injury, because IL- $1 \beta$ expression was almost completely abolished in MyD88-ko mice after sciatic nerve lesion. It is important to point out, however, that IL- $1 \beta$ synthesis was not completely prevented in TLR2-ko and TLR ${ }^{\mathrm{d}}$ mice, raising the possibility that compensatory mechanisms may exist among TLRs. Furthermore, because MCP-1 expression was only partly blocked in MyD88-ko mice, it seems likely that receptors signaling through MyD88-independent pathways may also participate in the innate immune response that rapidly develops after nervous system injury. In this regard, studies have shown that stimulation of MyD88-independent pathways through TLRs results in the expression of IFN-inducible genes (e.g., IFN $\beta$, IFN-inducible protein 10, iNOS) (Akira and Takeda, 2004). This is particularly relevant in light of our results showing the lack of expression of IFN-inducible genes (IFN $\beta$ and $i N O S$ ) during the first $24 \mathrm{~h}$ after sciatic nerve lesion, indicating that MyD88-independent TLR pathways are unlikely to play a role in the early events leading to macrophage recruitment/activation and WD. Recent studies have suggested that nucleotides released after CNS injury and acting through purinergic receptors could also serve as signals for the rapid response of brain resident macrophages (Davalos et al., 2005; Haynes et al., 2006). Because the identification of the signals and receptors that regulate the early stages of the innate immune response after nervous system injury is just starting to emerge, future studies should help better understand these issues.
Using a brain lesion model, Babcock et al. (2006) have recently demonstrated that TLR2, but not TLR4, is important for early cytokine/chemokine expression and microglial responses such as activation and proliferation. Although they found that TNF and MIP- $1 \alpha$ mRNA levels were significantly reduced in the lesionreactive hippocampus of TLR2-ko mice compared with wildtype animals at $3 \mathrm{~h}$ after lesion, IL- $1 \beta$ and MCP-1 mRNA levels were similar in those two groups. Another important finding of their study was that leukocyte infiltration was not affected by the absence of TLR2 signaling. We explain these discrepancies between our study and theirs by the presence of Schwann cells in our model. Schwann cells in culture have been shown to express several TLRs, including TLR2, TLR3, and TLR4 (Karanth et al., 2006; Lee et al., 2006). They are also the main cellular source of MCP-1 for the first few hours after peripheral nerve injury (Taskinen and Roytta, 2000), a process that appears to be partially initiated by the stimulation of TLR 4 on Schwann cells (Karanth et al., 2006). As demonstrated in vivo through infusion of functionblocking antibodies against MCP-1 or via the use of CCR2-ko mice, MCP-1 is essential for macrophage recruitment and myelin debris clearance during WD in the injured PNS (Siebert et al., 2000; Perrin et al., 2005). IL- $1 \beta$ is another proinflammatory cytokine rapidly upregulated by Schwann cells after PNS injury (Shamash et al., 2002). We found that neutralizing IL- $1 \beta$ through infusion of function-blocking antibodies into the injured sciatic nerve reduced the number of recruited macrophages by $42 \%$ and the number of phagocytic macrophages containing myelin debris by $69 \%$, therefore slowing down the process of WD (Perrin et al., $2005)$. In the present study, the levels of IL- $1 \beta$ and MCP-1 mRNAs and IL- $1 \beta$ protein in the sciatic nerve distal stump were significantly reduced in the absence of TLR2, TLR4, or MyD88. All these findings support a role for TLRs in macrophage recruitment and myelin debris clearance during WD, the end result of which has direct consequences on peripheral nerve regeneration most likely attributable to the presence of inhibitors of axonal regeneration associated with myelin debris.

It is not clear at present what endogenous ligands stimulate TLR signaling and initiate immune responses in degenerating peripheral nerves, nor was it the aim of the present study to identify these factors. Potential ligands include necrotic cells, HSPs, and ECM molecules (for review, see Takeda et al., 2003). However, the fact that MCP-1 expression precedes the appearance of axonal and myelin debris in the injured PNS [the first signs of axonal fragmentation distal to the lesion are typically seen after 36-44 h after injury (Beirowski et al., 2005)] does not support the possibility that necrotic cells are responsible for initiating innate immune responses during WD. Nevertheless, because MCP-1 expression is considerably delayed in peripheral nerves of Wld ${ }^{\text {s }}$ mutant mice (Carroll and Frohnert, 1998), and because early cytokine expression after nerve injury can be blocked by pretreatment with a calpain inhibitor (calpain is known to disassemble cytoskeletal proteins after axonal damage) (Uceyler et al., 2007), it is tempting to speculate that the endogenous ligand(s) responsible for TLR activation is released by degenerating axons. In this regard, a study by Willis and Twiss (2006) has recently identified $>100$ distinct axonally synthesized proteins, including several HSPs, in lesioned dorsal root ganglion sensory axons. However, it remains controversial whether HSPs function as endogenous ligands for TLRs based on numerous recent studies that have carefully excluded pathogen-derived molecules from recombinant HSP preparations (Gao and Tsan, 2003; Tsan and Gao, 2004; Ye and Gan, 2007). Another possibility is that specific ECM molecules may be rapidly released by pro- 
teases during the process of axonal disintegration and could then stimulate TLRs. Supporting this hypothesis is a study by Brunn et al. (2005), which demonstrated that TLR4 signaling was constitutively inhibited by ECM in intact tissues and that this inhibition was relieved when the matrix was degraded. They also found that components of the ECM, such as heparan sulfate, were released after matrix degradation in vivo and further contribute to TLR4 activation (Brunn et al., 2005). However, a recent study by Karanth et al. (2006) in which they measure MCP-1 mRNA synthesis by Schwann cells treated with putative TLR ligands has once again raised some doubts about the implication of HSP60, HSP70, and heparan sulfate in TLR activation after nerve damage. Rather, their in vitro model implicates a soluble protein of $1-10 \mathrm{kDa}$ as one of the ligands for TLRs in damaged nerve tissues (Karanth et al., 2006). Future studies should help identify the host-derived ligand(s) that stimulates TLRs after axonal injury.

In recent years, several studies have emerged from the rapidly growing interest in the roles of TLRs in the mammalian nervous system under nonpathogenic conditions (for review, see Kielian, 2006). One particularly intriguing observation came from the work of the Benowitz group, which showed that when injected directly into the eye, zymosan activated macrophages and induced regeneration of retinal ganglion cell axons into the lesioned optic nerve or into peripheral nerve grafts (Leon et al., 2000; Yin et al., 2003). This group later identified oncomodulin as a potent macrophage-derived factor with axon growthpromoting properties for retinal ganglion cells and dorsal root ganglion neurons (Yin et al., 2006). Herein, we showed that WD, axonal regeneration, and recovery of locomotor functions after sciatic nerve lesion are significantly delayed in mice deficient in TLR signaling but accelerated after a single microinjection of either zymosan (TLR2) or LPS (TLR4) at the site of injury. Whether oncomodulin is responsible for peripheral nerve regeneration after TLR activation in our experimental model remains to be investigated.

We reported in a previous study that systemic injections of LPS in mice can accelerate myelin debris clearance during WD in the injured spinal cord (Vallières et al., 2006). We also established that LPS treatment was not sufficient to promote regeneration of ascending sensory tract axons, despite enduring evidence that systemic LPS injections may support regeneration of spinal cordinjured axons (Windle, 1956; Guth et al., 1994). Factors that may have prevented axonal regeneration after SCI include the possibility that LPS treatment was not sufficient by itself to activate the intrinsic growth state program of lesioned neurons and the presence of inhibitory molecules associated to the glial scar. This is supported by the recent finding of Fischer et al. (2004), who reported that counteracting myelin inhibitors will enhance axon regeneration only if neurons are in an active growth state, and by our results showing the presence of a dense astrocytic scar surrounding ascending sensory tract axons in dorsal-hemisected mice (Vallières et al., 2006). On the basis of data obtained in the present study and the lack of evidence that injured neurons express TLRs, we propose that contradictory results seen in the SCI model compared with the PNS lesion model in terms of axonal regeneration may be once again linked to the presence of Schwann cells. However, although Schwann cells can clearly support axon growth through factors that they release, whether these factors are released in response to TLR activation remains to be demonstrated.

That TLRs may exert divergent effects in different injury models appears not to be limited to the issue of axonal regeneration. Several studies have shown that inflammation caused by the ac- tivation of TLR2 and TLR4 in the CNS can result in tissue damage and, in some cases, behavioral deficits (Fitch et al., 1999; Lehnardt et al., 2002, 2003, 2006; Popovich et al., 2002; Hoffmann et al., 2007). In contrast, systemic LPS injections in rats apparently reduce spinal cord cavitation after crush injury (Guth et al., 1994). Using a spinal cord contusion model, Kigerl et al. (2007) have recently found that locomotor recovery was impaired in TLR2-ko and TLR4 ${ }^{\mathrm{d}}$ mice, suggesting once again that TLR signaling may confer some form of neuroprotection after injury. Finally, we report here that a single intraneural injection of either zymosan or LPS significantly improved hindlimb functions. One should take into consideration, however, that zymosan or LPS was injected into the sciatic nerve distal stump in this study. We can therefore presume that TLR2 and TLR4 ligands and the potentially neurotoxic factors that may have been produced in response to these ligands were only in contact with axonal segments that were disconnected from their cell bodies and therefore already in the process of undergoing degeneration. Although we did not investigate whether treatment with TLR agonists leads to increased neuronal survival, we believe this possibility unlikely considering that $<2.5 \%$ of all L5 dorsal root ganglion neurons and spinal cord motor neurons projecting into the sciatic nerve normally die in our lesion model in adult rodents (S. Lacroix, unpublished observations). Together, these studies suggest that activation of TLR signaling may support neuronal survival and axonal regeneration under certain conditions and be detrimental in other circumstances. This may depend on several factors, including the cells that are activated, timing of activation, transduction signals involved, and cellular environment.

In light of our results showing the importance of TLR signaling in myelin debris clearance and peripheral nerve regeneration, we were interested in finding out whether administration of synthetic glucocorticoids would compromise regeneration in our sciatic nerve lesion model. The scientific rationale for using synthetic glucocorticoids (DEX and MP) instead of nonsteroidal anti-inflammatory drugs was based on the following: (1) synthetic glucocorticoids have been shown to inhibit transcription of most genes involved in innate immune responses, including NF- $\kappa \mathrm{B}$ signaling pathways (Glezer and Rivest, 2004; Sternberg, 2006); and (2) synthetic glucocorticoids have been used for years in the clinic to treat traumatic spinal cord and nerve injuries (David and Lacroix, 2005; Steinsapir, 2006). Our results revealed that macrophage infiltration and myelin debris clearance in the sciatic nerve distal stump are greatly inhibited by the administration of high doses of DEX, whereas a nonsignificant trend in these responses was observed after MP treatment. Even more important was the fact that recovery of locomotor functions was significantly delayed in DEX-treated rats. It is also worth mentioning that sciatic functions in DEX-treated rats never recovered to levels equivalent to presurgical performances at any of the time points analyzed in the present study (i.e., up to $49 \mathrm{~d}$ after lesion). It should be pointed out, however, that MP-treated animals had completely recovered by $42 \mathrm{~d}$ after sciatic nerve lesion compared with $28 \mathrm{~d}$ for control rats. The difference between DEX and MP may depend on the availability of both synthetic glucocorticoids to inhibit NF- $\kappa \mathrm{B}$ and transcriptional activation of immune genes. DEX is, by far, the most potent agonist of glucocorticoid receptors and is extremely powerful in inhibiting innate immune responses in the CNS (Glezer and Rivest, 2004). These data together provide solid evidence that TLR signaling and innate immune responses play a critical role in clearance of inhibitory myelin debris and set the conditions for nerve regeneration and repair. This concept will have a direct impact on the development of new 
therapeutic strategies to treat patients suffering from nerve injuries and prevent long-term consequences of regeneration failure.

\section{References}

Akira S, Takeda K (2004) Toll-like receptor signalling. Nat Rev Immunol 4:499-511.

Babcock AA, Wirenfeldt M, Holm T, Nielsen HH, Dissing-Olesen L, ToftHansen H, Millward JM, Landmann R, Rivest S, Finsen B, Owens T (2006) Toll-like receptor 2 signaling in response to brain injury: an innate bridge to neuroinflammation. J Neurosci 26:12826-12837.

Bain JR, Mackinnon SE, Hunter DA (1989) Functional evaluation of complete sciatic, peroneal, and posterior tibial nerve lesions in the rat. Plast Reconstr Surg 83:129-138.

Basso DM, Beattie MS, Bresnahan JC (1996) Graded histological and locomotor outcomes after spinal cord contusion using the NYU weight-drop device versus transection. Exp Neurol 139:244-256.

Behrmann DL, Bresnahan JC, Beattie MS, Shah BR (1992) Spinal cord injury produced by consistent mechanical displacement of the cord in rats: behavioral and histologic analysis. J Neurotrauma 9:197-217.

Beirowski B, Adalbert R, Wagner D, Grumme DS, Addicks K, Ribchester RR, Coleman MP (2005) The progressive nature of Wallerian degeneration in wild-type and slow Wallerian degeneration (WldS) nerves. BMC Neurosci 6:6.

Beuche W, Friede RL (1984) The role of non-resident cells in Wallerian degeneration. J Neurocytol 13:767-796.

Bracken MB, Shepard MJ, Collins WF, Holford TR, Young W, Baskin DS, Eisenberg HM, Flamm E, Leo-Summers L, Maroon J, et al. (1990) A randomized, controlled trial of methylprednisolone or naloxone in the treatment of acute spinal-cord injury. Results of the Second National Acute Spinal Cord Injury Study. N Engl J Med 322:1405-1411.

Bracken MB, Shepard MJ, Holford TR, Leo-Summers L, Aldrich EF, Fazl M, Fehlings M, Herr DL, Hitchon PW, Marshall LF, Nockels RP, Pascale V, Perot Jr PL, Piepmeier J, Sonntag VK, Wagner F, Wilberger JE, Winn HR, Young W (1997) Administration of methylprednisolone for 24 or 48 hours or tirilazad mesylate for 48 hours in the treatment of acute spinal cord injury. Results of the Third National Acute Spinal Cord Injury Randomized Controlled Trial. National Acute Spinal Cord Injury Study. JAMA 277:1597-1604.

Brown MC, Perry VH, Lunn ER, Gordon S, Heumann R (1991) Macrophage dependence of peripheral sensory nerve regeneration: possible involvement of nerve growth factor. Neuron 6:359-370.

Bruck W, Huitinga I, Dijkstra CD (1996) Liposome-mediated monocyte depletion during Wallerian degeneration defines the role of hematogenous phagocytes in myelin removal. J Neurosci Res 46:477-484.

Brunn GJ, Bungum MK, Johnson GB, Platt JL (2005) Conditional signaling by Toll-like receptor 4. FASEB J 19:872-874.

Carroll SL, Frohnert PW (1998) Expression of JE (monocyte chemoattractant protein-1) is induced by sciatic axotomy in wild type rodents but not in C57BL/Wld. (s) mice. J Neuropathol Exp Neurol 57:915-930.

Choucair N, Laporte V, Levy R, Arnold A-S, Gies J-P, Poindron P, Lombard Y (2006) Phagocytic functions of microglial cells in the central nervous system and their importance in two neurodegenerative diseases: multiple sclerosis and Alzheimer's disease. Central Eur J Biol 1:463-493.

Davalos D, Grutzendler J, Yang G, Kim JV, Zuo Y, Jung S, Littman DR, Dustin ML, Gan WB (2005) ATP mediates rapid microglial response to local brain injury in vivo. Nat Neurosci 8:752-758.

David S, Lacroix S (2003) Molecular approaches to spinal cord repair. Annu Rev Neurosci 26:411-440.

David S, Lacroix S (2005) Role of the immune response in tissue damage and repair in the injured spinal cord. In: Clinical neuroimmunology, Ed 2 (Antel J, Birnbaum G, Hartung HP, Vincent A, eds), pp 53-63. Oxford: Oxford UP.

de Medinaceli L, Freed WJ, Wyatt RJ (1982) An index of the functional condition of rat sciatic nerve based on measurements made from walking tracks. Exp Neurol 77:634-643.

Fernandez-Valle C, Bunge RP, Bunge MB (1995) Schwann cells degrade myelin and proliferate in the absence of macrophages: evidence from in vitro studies of Wallerian degeneration. J Neurocytol 24:667-679.

Fischer D, He Z, Benowitz LI (2004) Counteracting the Nogo receptor enhances optic nerve regeneration if retinal ganglion cells are in an active growth state. J Neurosci 24:1646-1651.

Fitch MT, Doller C, Combs CK, Landreth GE, Silver J (1999) Cellular and molecular mechanisms of glial scarring and progressive cavitation: in vivo and in vitro analysis of inflammation-induced secondary injury after CNS trauma. J Neurosci 19:8182-8198.

Fu SY, Gordon T (1997) The cellular and molecular basis of peripheral nerve regeneration. Mol Neurobiol 14:67-116.

Gao B, Tsan MF (2003) Endotoxin contamination in recombinant human heat shock protein $70(\mathrm{Hsp} 70)$ preparation is responsible for the induction of tumor necrosis factor alpha release by murine macrophages. J Biol Chem 278:174-179.

George A, Buehl A, Sommer C (2004) Wallerian degeneration after crush injury of rat sciatic nerve increases endo- and epineurial tumor necrosis factor-alpha protein. Neurosci Lett 372:215-219.

Glezer I, Rivest S (2004) Glucocorticoids: protectors of the brain during innate immune responses. Neuroscientist 10:538-552.

Guth L, Zhang Z, DiProspero NA, Joubin K, Fitch MT (1994) Spinal cord injury in the rat: treatment with bacterial lipopolysaccharide and indomethacin enhances cellular repair and locomotor function. Exp Neurol 126:76-87.

Haynes SE, Hollopeter G, Yang G, Kurpius D, Dailey ME, Gan WB, Julius D (2006) The P2Y12 receptor regulates microglial activation by extracellular nucleotides. Nat Neurosci 9:1512-1519.

Heumann R, Lindholm D, Bandtlow C, Meyer M, Radeke MJ, Misko TP, Shooter E, Thoenen H (1987) Differential regulation of mRNA encoding nerve growth factor and its receptor in rat sciatic nerve during development, degeneration, and regeneration: role of macrophages. Proc Natl Acad Sci USA 84:8735-8739.

Hoffmann O, Braun JS, Becker D, Halle A, Freyer D, Dagand E, Lehnardt S, Weber JR (2007) TLR2 mediates neuroinflammation and neuronal damage. J Immunol 178:6476-6481.

Inserra MM, Bloch DA, Terris DJ (1998) Functional indices for sciatic, peroneal, and posterior tibial nerve lesions in the mouse. Microsurgery 18:119-124.

Inserra MM, Yao M, Murray R, Terris DJ (2000) Peripheral nerve regeneration in interleukin 6-deficient mice. Arch Otolaryngol Head Neck Surg 126:1112-1116.

Karanth S, Yang G, Yeh J, Richardson PM (2006) Nature of signals that initiate the immune response during Wallerian degeneration of peripheral nerves. Exp Neurol 202:161-166.

Karnezis T, Mandemakers W, McQualter JL, Zheng B, Ho PP, Jordan KA, Murray BM, Barres B, Tessier-Lavigne M, Bernard CC (2004) The neurite outgrowth inhibitor Nogo A is involved in autoimmune-mediated demyelination. Nat Neurosci 7:736-744.

Kielian T (2006) Toll-like receptors in central nervous system glial inflammation and homeostasis. J Neurosci Res 83:711-730.

Kigerl KA, Rivest S, Hart RP, Satoska AR, Popovich PG (2007) Toll-like receptor-mediated activation of innate immunity is important for recovery after spinal cord injury. J Neurochem, in press.

Krekoski CA, Neubauer D, Graham JB, Muir D (2002) Metalloproteinasedependent predegeneration in vitro enhances axonal regeneration within acellular peripheral nerve grafts. J Neurosci 22:10408-10415.

La Fleur M, Underwood JL, Rappolee DA, Werb Z (1996) Basement membrane and repair of injury to peripheral nerve: defining a potential role for macrophages, matrix metalloproteinases, and tissue inhibitor of metalloproteinases-1. J Exp Med 184:2311-2326.

Lee H, Jo EK, Choi SY, Oh SB, Park K, Kim JS, Lee SJ (2006) Necrotic neuronal cells induce inflammatory Schwann cell activation via TLR2 and TLR3: implication in Wallerian degeneration. Biochem Biophys Res Commun 350:742-747.

Lehnardt S, Lachance C, Patrizi S, Lefebvre S, Follett PL, Jensen FE, Rosenberg PA, Volpe JJ, Vartanian T (2002) The toll-like receptor TLR4 is necessary for lipopolysaccharide-induced oligodendrocyte injury in the CNS. J Neurosci 22:2478-2486.

Lehnardt S, Massillon L, Follett P, Jensen FE, Ratan R, Rosenberg PA, Volpe JJ, Vartanian T (2003) Activation of innate immunity in the CNS triggers neurodegeneration through a Toll-like receptor 4-dependent pathway. Proc Natl Acad Sci USA 100:8514-8519.

Lehnardt S, Henneke P, Lien E, Kasper DL, Volpe JJ, Bechmann I, Nitsch R, Weber JR, Golenbock DT, Vartanian T (2006) A mechanism for neurodegeneration induced by group $\mathrm{B}$ streptococci through activation of the TLR2/MyD88 pathway in microglia. J Immunol 177:583-592.

Leon S, Yin Y, Nguyen J, Irwin N, Benowitz LI (2000) Lens injury stimulates 
axon regeneration in the mature rat optic nerve. J Neurosci 20:4615-4626.

Liefner M, Siebert H, Sachse T, Michel U, Kollias G, Bruck W (2000) The role of TNF-alpha during Wallerian degeneration. J Neuroimmunol 108:147-152.

Lindholm D, Heumann R, Meyer M, Thoenen H (1987) Interleukin-1 regulates synthesis of nerve growth factor in non-neuronal cells of rat sciatic nerve. Nature 330:658-659.

Liu J, Marino MW, Wong G, Grail D, Dunn A, Bettadapura J, Slavin AJ, Old L, Bernard CC (1998) TNF is a potent anti-inflammatory cytokine in autoimmune-mediated demyelination. Nat Med 4:78-83.

Lunn ER, Perry VH, Brown MC, Rosen H, Gordon S (1989) Absence of Wallerian degeneration does not hinder regeneration in peripheral nerve. Eur J Neurosci 1:27-33.

Ma M, Basso DM, Walters P, Stokes BT, Jakeman LB (2001) Behavioral and histological outcomes following graded spinal cord contusion injury in the C57Bl/6 mouse. Exp Neurol 169:239-254.

Ma M, Wei T, Boring L, Charo IF, Ransohoff RM, Jakeman LB (2002) Monocyte recruitment and myelin removal are delayed following spinal cord injury in mice with CCR2 chemokine receptor deletion. J Neurosci Res 68:691-702.

Mueller M, Leonhard C, Wacker K, Ringelstein EB, Okabe M, Hickey WF, Kiefer R (2003) Macrophage response to peripheral nerve injury: the quantitative contribution of resident and hematogenous macrophages. Lab Invest 83:175-185.

Nguyen MD, Julien JP, Rivest S (2002) Innate immunity: the missing link in neuroprotection and neurodegeneration? Nat Rev Neurosci 3:216-227.

Noble LJ, Wrathall JR (1989) Correlative analyses of lesion development and functional status after graded spinal cord contusive injuries in the rat. Exp Neurol 103:34-40.

Perrin FE, Lacroix S, Aviles-Trigueros M, David S (2005) Involvement of monocyte chemoattractant protein-1, macrophage inflammatory protein-1alpha and interleukin-1beta in Wallerian degeneration. Brain 128:854-866.

Pineau I, Lacroix S (2007) Proinflammatory cytokine synthesis in the injured mouse spinal cord: multiphasic expression pattern and identification of the cell types involved. J Comp Neurol 500:267-285.

Popovich PG, Guan Z, Wei P, Huitinga I, van Rooijen N, Stokes BT (1999) Depletion of hematogenous macrophages promotes partial hindlimb recovery and neuroanatomical repair after experimental spinal cord injury. Exp Neurol 158:351-365.

Popovich PG, Guan Z, McGaughy V, Fisher L, Hickey WF, Basso DM (2002) The neuropathological and behavioral consequences of intraspinal microglial/macrophage activation. J Neuropathol Exp Neurol 61:623-633.

Pot C, Simonen M, Weinmann O, Schnell L, Christ F, Stoeckle S, Berger P, Rulicke T, Suter U, Schwab ME (2002) Nogo-A expressed in Schwann cells impairs axonal regeneration after peripheral nerve injury. J Cell Biol 159:29-35.

Reynolds ML, Woolf CJ (1993) Reciprocal Schwann cell-axon interactions. Curr Opin Neurobiol 3:683-693.

Sawada T, Sano M, Omura T, Omura K, Hasegawa T, Funahashi S, Nagano A (2007) Spatiotemporal quantification of tumor necrosis factor-alpha and interleukin-10 after crush injury in rat sciatic nerve utilizing immunohistochemistry. Neurosci Lett 417:55-60.
Sergerie Y, Boivin G, Gosselin D, Rivest S (2007) Delayed but not early glucocorticoid treatment protects the host during experimental herpes simplex virus encephalitis in mice. J Infect Dis 195:817-825.

Shamash S, Reichert F, Rotshenker S (2002) The cytokine network of Wallerian degeneration: tumor necrosis factor- $\alpha$, interleukin- $1 \alpha$, and interleukin-1 $\beta$. J Neurosci 22:3052-3060.

Siebert H, Sachse A, Kuziel WA, Maeda N, Bruck W (2000) The chemokine receptor CCR2 is involved in macrophage recruitment to the injured peripheral nervous system. J Neuroimmunol 110:177-185.

Steinsapir KD (2006) Treatment of traumatic optic neuropathy with highdose corticosteroid. J Neuroophthalmol 26:65-67.

Sternberg EM (2006) Neural regulation of innate immunity: a coordinated nonspecific host response to pathogens. Nat Rev Immunol 6:318-328.

Stoll G, Griffin JW, Li CY, Trapp BD (1989) Wallerian degeneration in the peripheral nervous system: participation of both Schwann cells and macrophages in myelin degradation. J Neurocytol 18:671-683.

Stoll G, Jander S, Myers RR (2002) Degeneration and regeneration of the peripheral nervous system: from Augustus Waller's observations to neuroinflammation. J Peripher Nerv Syst 7:13-27.

Subang MC, Richardson PM (2001) Influence of injury and cytokines on synthesis of monocyte chemoattractant protein-1 mRNA in peripheral nervous tissue. Eur J Neurosci 13:521-528.

Takeda K, Kaisho T, Akira S (2003) Toll-like receptors. Annu Rev Immunol 21:335-376.

Taskinen HS, Roytta M (2000) Increased expression of chemokines (MCP-1, MIP-1alpha, RANTES) after peripheral nerve transection. J Peripher Nerv Syst 5:75-81.

Tsan MF, Gao B (2004) Heat shock protein and innate immunity. Cell Mol Immunol 1:274-279.

Uceyler N, Tscharke A, Sommer C (2007) Early cytokine expression in mouse sciatic nerve after chronic constriction nerve injury depends on calpain. Brain Behav Immun 21:553-560.

Vallières N, Berard JL, David S, Lacroix S (2006) Systemic injections of lipopolysaccharide accelerates myelin phagocytosis during Wallerian degeneration in the injured mouse spinal cord. Glia 53:103-113.

Willis D, Li KW, Zheng JQ, Chang JH, Smit A, Kelly T, Merianda TT, Sylvester J, van Minnen J, Twiss JL (2005) Differential transport and local translation of cytoskeletal, injury-response, and neurodegeneration protein mRNAs in axons. J Neurosci 25:778-791.

Willis DE, Twiss JL (2006) The evolving roles of axonally synthesized proteins in regeneration. Curr Opin Neurobiol 16:111-118.

Windle WF (1956) Regeneration of axons in the vertebrate central nervous system. Physiol Rev 36:427-440.

Ye Z, Gan YH (2007) Flagellin contamination of recombinant heat shock protein 70 is responsible for its activity on $\mathrm{T}$ cells. J Biol Chem 282:4479-4484.

Yin Y, Cui Q, Li Y, Irwin N, Fischer D, Harvey AR, Benowitz LI (2003) Macrophage-derived factors stimulate optic nerve regeneration. J Neurosci 23:2284-2293.

Yin Y, Henzl MT, Lorber B, Nakazawa T, Thomas TT, Jiang F, Langer R, Benowitz LI (2006) Oncomodulin is a macrophage-derived signal for axon regeneration in retinal ganglion cells. Nat Neurosci 9:843-852. 